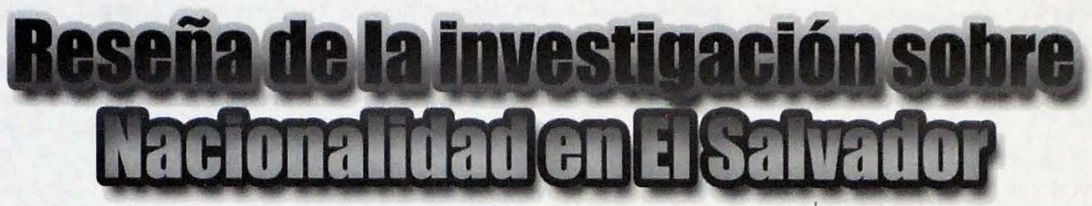

Por: Bi.anc.A Ruth Orantes

$\mathrm{E}$ ste artículo pretende constituir una aproximación al estudio de la nacionalidad como instirución juridica y polírica. La nacionalidad se puede estudiar desde varias ramas del derecho, por ejemplo Derecho Constitucional, Derecho Internacional Privado, Derecho Civil, entre otras.

No obstante, esta institución está vinculada a la historia misma del ser humano y al entorno que lo rodea, llegando a niveles de organización que le exige una identidad con ese entorno. Lo antes planteado nos lleva a ubicar a la nacionalidad, no de una forma abstracta en el mundo del derecho, sino más bien vinculada con el entorno socio político que desarrolla toda sociedad, de ahi su relación con las ciencias sociales.

Sobre la base expuesta, realizar un estudio sobre la figura de la nacionalidad implica partir de la historia misma, auxiliándose de las ciencias sociales de una forma general y las ciencias jurídicas en particular; hasta llegar al desarrollo de la norma jurídica en las ciencias del derecho.

De ahí que en la investigación titulada "La nacionalidad de la per sona natural en El Salvador" se encuentre un enfoque histórico y jurídico, lo cual permite un estudio novedoso y comprensible de esta institución, tanto para conocedores como para interesados en el tema.

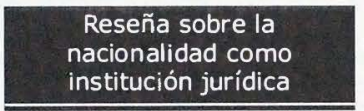

I a investigación sobre la nacioL nalidad contiene aspectos conceptuales, históricos y juridicos y pretende ser un documento de consulta

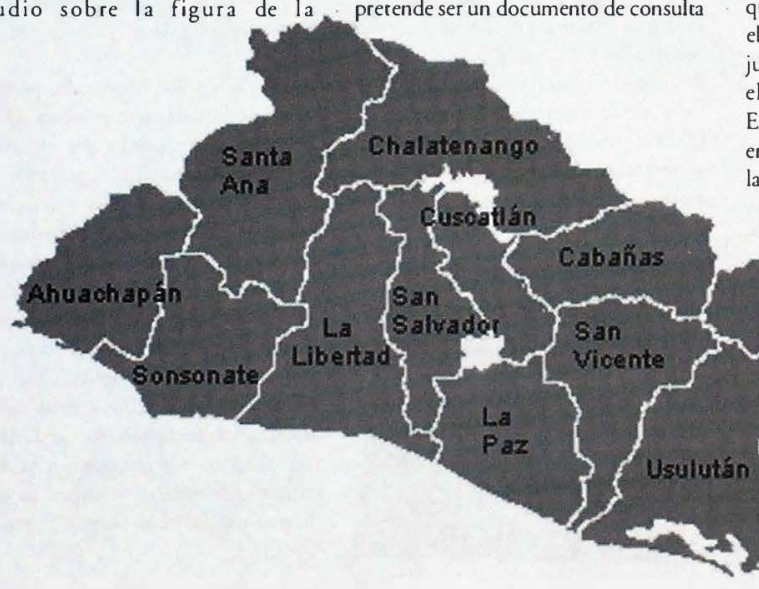

para profesionales e interesados en el rema.

Este artículo recoge los puntos de mayor relevancia abordados en la mencionada investigación, la cual además se encuentra en la página Web de la Universidad Tecnológica de El Salvador (UTEC).

En lo que se refiere a la parte conceptual, son dos los conceptos básicos: nacionalidad de origen y naturalización. La nacionalidad de origen es llamada también natural por nacimiento o simplemente nacionalidad. A la naruralización en muchos países se le denomina nacionalidad jurídica o adquirida; a su vez, la naturalización puede obrenerse por voluntad propia, forzada o por honor.

La nacionalidad ha sido un concepto que se institucionalizó cuando surgió el Estado y se establece un vínculo jurídico-político entre sus nacionales y el sistema en el que se erige dicho Estado, de ahí que surgiera de hecho en el momento mismo que se desarrolla la identidad con determinada sociedad,

\title{
thor
}

b

8


por lazos de sangre, de suelo, pero sobre rodo en donde la persona pueda desarrollarse, de no ser así, éstas deciden emigrar hacia otras naciones.

Si la nacionalidad se desarrolló por ese vínculo afectivo hacia determinada nación, fue necesario que el derechola regulara, es decir, que la normara; aunque la norma jurídica establece la competencia del Estado para otorgarla, también para que por voluntad propia se acceda a esa nacionalidad.

\section{Problemática surgida} respecto a la Nacionalidad

T a nacionalidad, de acuerdo a la Ldoctrina y el derecho, puede concederse tanto a personas naturales como a personas jurídicas. En este caso la investigación se centró básicamente en la nacionalidad de la persona natural. ¿ Por qué esta selección? En los trámites de la persona narural es donde se encuentran los mayores conflictos de nacionalidad, es decir el asunto de la doble y múltiple nacionalidad, los sistemas del Jus soli (Derecho al suelo) $y$ el Jus sanguinis (Derecho de la sangre), entre otros.

Estos conflictos de nacionalidad se manifiestan de diferente forma como comprender la magnitud de la doble y múlriple nacionalidad, es decir, que existen normas que establecen límites para prevenirlos.

No obstante, aún cuando la Constirución de la República expresamente establece las formas de otorgar la nacionalidad a las personas naturales, le sigue la Ley de Extranjería y algunas disposiciones de la Ley de Migración y el Código Civil, regulando siempre algunos aspectos sobre esa figura, el problema radica en la forma de que las personas entienden su regulación.

Por ejemplo, la Constitución de la República de El Salvador, dice en su arrículo 90 , ordinal $3^{\circ}$. que los centroamericanos "son salvadoreños por nacimiento si manifestaren su voluntad de serlo ante autoridad competente". Significa que pueden optar por una nacionalidad privilegiada' (por nacimiento).

Esto en el pasado dio lugar a que en muchas alcaldías, sin que los extranjeros centroamericanos hubieren realizado su trámite de nacionalidad ante el Ministerio de Gobernación (MG) y solamente mostrando su cerrificado de nacimiento del país que provenian, se les extendiera a algunos centroamericanos, más que todo de los países de Honduras, Nicaragua y Guatemala, la antigua Cédula de Identidad Personal (derogada), procediendo a sacar otros documentos (tarjeta del Instituto Salvadoreño del Seguro Social (ISSS), Número de Identificación Triburaria (NIT), Etc.) como si fueran nacionales, $y$ así han residido durante años.

El problema surge con mayor fuerza, cuando estas personas se acercan a los Duicentros a que se les extienda su Documento Único de Identidad (DUI), y cuando ellos se dan cuenta que no poseen su cerrificado de nacimiento de El Salvador, que deberia de ser Carta de Naturalización extendida por MG, se acercan a pedir asesoría, ya sea en sus embajadas acreditadas en nuestro país u oficinas de asesoría legal, tal como la que se tiene en la Universidad Tecnológica (UTEC), en donde se brinda atención a personas que requieren de dicha asesoría, que para el caso sería asesoría migratoria.

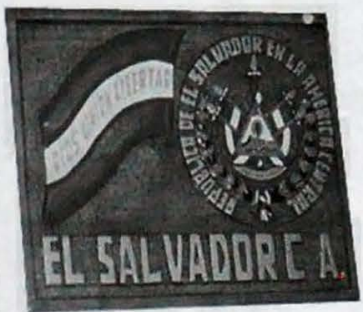

Estas personas se acercan con mucha preocupación, pues en ocasiones ni en sus embajadas pueden darle una salida alterna a su problema, y no van a Migración porque temen ser expulsados de El Salvador.

Lo anterior constituyen solamente algunos de los problemas que han surgido de la no interpretación adecuada de la norma, a lo cual hay que agregar categóricamente que no se puede aducir ignorancia a la ley por nadie, ni por nacionales ni extranjeros, tal como lo manifiesta el Arr. 8 de nuestro Código Civil.

Problemas como el anterior motivaron a realizar esta investigación sobre la nacionalidad, buscando hacer un estudio completo de su evolución y su regulación jurídica

Procedimiento legal para adquirir la Nacionalidad

C 1 Ministerio de Gobernación hace Cuna gran labor con la difusión en su página $W^{2} B^{2}$ sobre algunos trámites y requisitos a realizar en sus instancias, no obstante no toda la población tiene acceso a este medio, por lo que algunos se acercan a las oficinas de este Ministerio y a oficinas de asesoría legal.

Sin embargo, son muchas las personas que requieren conocer acerca de este procedimiento, por lo que un estudio sobre la nacionalidad, permitiría a muchos profesionales del derecho, a cónsules centroamericanos, incluyendo a sus colaboradores, a funcionarios y empleados del MG en las instancias pertinentes, profesionales, profesores y estudiantes de las distintas ramas del derecho, así como público en general interesados en el rema, contar con un documento completo, el cual puede ser actualizado en la medida que las leyes afines se reformen, no asi en su parte histórica, la cual forma parte del pasado. 


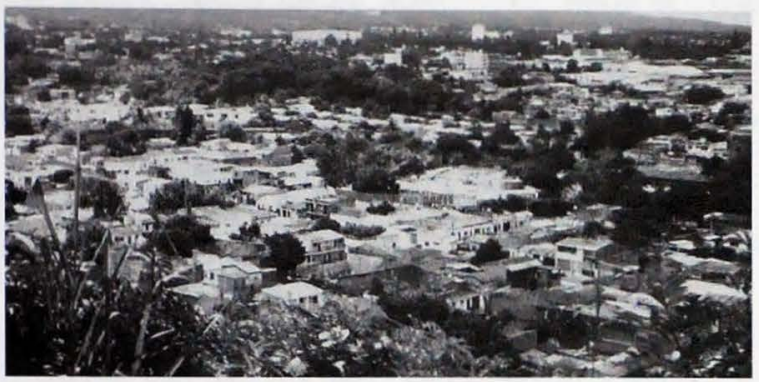

No obstance, se deberían realizar campañas de divulgación tanto en el ámbito nacional como internacional para evit ar que las personas no tramiren oportunamente su nacionalidad, para que se eviten los conflicros de la doble nacionalidad y sobre todo evitar los apátridas. No hay que olvidar que el derecho a la nacionalidad es un derecho fundamencal, pero que al mismo se le deben establecer límites legales.

En nuestra universidad se brinda actualmente asesoria migratoria, procurando dar la mejor asesoría, con el objeto de brindar una solución legal a los casos que se presentan, por supuesto, dentro dela competencia que la ley permite.

En su mayoría se presentan casos de centroamericanos y muy pocos de Sur América o de otros paises. Dentro de los casos se encuentran: extranjeros que ingresaron ilegalmente, orros a quienes se les venció el permiso y no lo renovaron, algunos que contrajeron matrimonio con salvadoreños o salvadoreñas, pero que no legalizaron su permanencia en El Salvador.

Inclusive existen algunos extranjeros que para disfrazar su ilegalidad en el pais, han procedido principalmente en el pasado a legalizar su situación, según ellos, por medio de cédulas de identidad falsas, lo que les ha permitido trabajar en El Salvador, sin ningún problema, salvo el que han tenido al querersacar su DUI.
Aporte de la investigación sobre nacionalidad

entro de la visión y misión de la Universidad Tecnológica se encuentra forralecer la investigación y proyección social, gracias a ello se pueden realizar investigaciones como la de la nacionalidad, que viene a resolver el problema de no encontrar un estudio de tal magnitud, pues se encuentran análisis propiamente legales, dejando de lado cómo surge la nacionalidad y sus componentes, sus implicaciones hasta llegar a procedimientos analizados no sólo a la luz del precepto legal, sino complementando con la visita insritucional, que permitió validar la aplicabilidad de la norma, así como algunos procedimientos no contemplados en la misma.

En la Constitución de la República de El Salvador se establece que existen dos formas de otorgar la nacionalidad: la nacionalidad de origen regulada en el Art. $90 \mathrm{Cn}$. y la naturalización en el $92 \mathrm{Cn}$.

A su vez, en el Art. 90 se establece que son salvadoreńos por nacimiento: los nacidos en el territorio de la República de El Salvador, que está basado en el sistema Jus soli o Derecho al Suelo, significan al suelo en que se nace, está directamente regulado en el ordinal 10 . del mencionado Art. 90, siendo el límite a esta disposición el Art. 48 inciso segundo LM, que establece: "Los hijos de padres extranjeros nacidos en El Salvador deberán ser inscritos con cualesquiera de las Constancias de éstos, si fueren Residentes Definitivos $y$ en caso contrario se les concederá igual permanencia que a los padres. Quedan exceptuados los hijos de los Centroamericanos por nacimiento".

En este mismo orden, el ordinal $2^{\circ}$, siempre del Art. 90 establece que los hijos de padre o madre salvadoreños pueden optar por la nacionalidad de origen, sea porque sus padres los inscriban en el Consulado de El Salvador acreditadoen el país en donde se encuentren o los inscriban directamente en el Ministerio de Relaciones Exteriores en la Dirección de Servicio Exrerior. Significa que siempre hay que realizar un trámite, tal vez un poco menos burocrático.

El ordinal $3^{\circ}$ se refiere a los centroamericanos que conformaron la Federación Centroamericana en la época pos independentista, es decir, Guaremala, Honduras, Nicaragua y Costa Rica. Ellos pueden optar por la nacionalidad salvadoreña de origen, media ver realicen por voluntad propia el trámite ante el Ministerio de Gobernación (Art. 90 ordinal 30. Cn y $1 \mathrm{LE}$ ) y les conceda su nacionalidad, si no existieren inhabilidades de acuerdo al Arr. 32 inciso segundo LE, que literalmente dice:

"El Gobierno de El Salvador podrá negar a los exrranjeros la calidad de salvadoreño por naturalización, en los siguientes casos:

a) A los originarios de otro Estadocon el cual el país se encuentre en estado de guerra declarada o no;

b) A los extranjeros imputados, procesados o condenados por delitos cometidos en el territorio nacional o en país extranjero.

En iguales circunstancias, también podrá negar la calidad de salvadoreño 
por nacimiento a los originarios de los demás Estados que constituyeron la República Federal de Centro América".

Pero si no exisriere ninguna inhabilidad puede acceder a los beneficios de trato diferenciado que se les da a los centroamericanos. Es porlos lazos de sangre que los unían cuando era una sola nación en la época independentista y la lucha que realizaron juntos para desvincularse política y jurídicamente de España.

Uno de losbeneficiosespecialesque tiene la nacionalidad de origen es que permite la doble o múltiple nacionalidad según lo establece el Art. 91 inciso primero. Aunque el Art. $93 \mathrm{Cn}$., establece que pueden consetvar su nacionalidad, sin renunciarla, los naturalizados, si existiere un tratado internacionalentre losestados involucrados.

Además de poder renunciar a esa nacionalidad y recuperarla en el momento que lo requiera, ya sea porque le revocan la nacionalidad en ese tercer Estado en donde la adquirió o porque ya no desea seguir con esa nacionalidad.

Respecto a la naturalización, en el Art. 92 se encuentran cuatro literales que establecen las formas de otorgarla:

El ordinal $1^{\circ}$. dice que los hispanoamericanos y españoles pueden optar por naturalizarse en El Salvador después de un año de residencia y por supuesto llenar los requisitos que esrablece la Ley de Extranjería en los artículos 38 y siguientes.

Este trato de preferencia que se da a los hispanoamericanos y españoles, se supone obedece a lazos socio políticos que datan de la época de la Colonia, en donde los escados de habla hispana eran los que fueron colonizados por España. El procedimiento se hace ante el Ministerio de Gobernación.
El ordinal $2^{\circ}$ permite la naturalización a los nacionales de otros estados, con cinco años de residencia en $\mathrm{El}$ Salvador y por supuesto llenar los requisitos que esrablece la Ley de Extranjería (Art. 38 y siguientes). El procedimiento se hace ante el Ministerio de Gobernación.

El ordinal $3^{\circ}$. menciona que también se puede otorgar la nacionalidad por honor, siendo el trámite iniciado por la entidadu organización que propone a la persona nominada, ance la Comisión de Cultura y Educación de la Asamblea Legislativa, previo Ilenar los requisitos establecidos en la Ley de Extranjería.

El procedimiento de otorgación se rige por la Ley de Distinciones Honoríficas, Gracificaciones y Títulos. Para que sea efectiva esta naturalización se requiere que la persona interesada se presente al Ministerio de Gobernación para que se reconozca esa nacuralización otorgada mediante Decreto Legislativo.

El ordinal $4^{\circ}$. se refiere a la mujer u hombre casada o casada con salvadoreños, que si lo desean después de haber residido dos años antes o después del matrimonio pueden optar por la nacuralización, previo llenar requisitos establecidos en la Ley de Exrranjería.

Tanto para el ordinal 30. Del Arr. 90 Cn. Como para los ordinales $1^{\circ}$, , 20. $3^{\circ}$. y $4^{\circ}$. Cn. Existen inhabilidades establecidasen el Art.31 LE.

Para el caso de los naturalizados, a éstos se les puede revocar por las causales establecidas en el Arr. $94 \mathrm{Cn}$. Y en el caso del ordinal segundo, jamás podrían recuperarla. Es decir, en caso de sentencia ejecutoriada, aunque la Constitución ni la ley secundaria establece qué ripo de sentencia, se presume que ésta deberá ser condenatoria.
Consecuencias del sistema actual de Nacionalidad

Ce pudo constarar que se tiene un sistema de nacionalidad un tanto flexible, principalmente para los centroamericanos, españoles e hispanoamericanos, lo que sibien es cierto ha permitido que algunos de ellos creen fuentes de empleo invirtiendo en El Salvador, también se observa a muchos hondureños, nicaragüenses, peruanos, entre otros, han realizado su proceso de nacionalización en El Salvador, desplazando en alguna medida a los salvadoreños, tal es el caso que se encuentran muchos de ellos en la construcción, fábricas, comercio y otras empresas en el país, inclusive en instituciones educativas ejerciendo como docentes.

Por ello resulta necesario que en un futuro inmediato se realicen reformas a la Ley de Extranjería y Ley de Migración para incorporar la necesidad de ejercer un mayor control migratorio y sobre todo lo que compere a este rema, que la nacionalidad sea regulada de ral forma que se ororgue sin que signifique un riesgo para los salvadoreños por nacimiento, partiendo de que se tiene una población numerosa y los recursos son limitados, es decir, que no se debe conceder la nacionalidad a personas que puedan en alguna medida desplazar la mano de obra salvadoreña y el secror de profesionales.

Se deben seguir los ejemplos de países como Costa Rica y Honduras, quienes tienen sistemas verdaderamente protectores de los recursos nacionales, entre ellos el del recurso humano, es decir, sus nacionales de origen.

\section{Citas}

Privilegiada, porque pueden opera a cargos públicos de elección popular, que es exclusiva de los racionales por nacimiento.

Se puede visitar www.gobernacion.gob.svl o wwwservicios.geb.svl 